\title{
Crystal Structure of 5,10,15,20-Tetrakis\{[4-(allyloxy)phenyl]- porphyrinato\}zinc(II)
}

\author{
Hee-Joon KIM*广 and Ki-Min PARK** \\ *Department of Applied Chemistry, Kumoh National Institute of Technology, 1 Yangho-dong, \\ Gumi 730-701, Republic of Korea \\ **Research Institute of Natural Sciences, Gyeongsang National University, Chinju 660-701, Republic of Korea
}

\begin{abstract}
The structure of the title compound, $\left[\mathrm{Zn}\left(\mathrm{C}_{56} \mathrm{H}_{44} \mathrm{~N}_{4} \mathrm{O}_{4}\right)\right]$, was confirmed by low-temperature single-crystal analysis. The crystal system belongs to monoclinic with space group of $P 2_{1} / n$. The crystal structure reveals that the $\mathrm{Zn}^{\mathrm{II}}$ center adopts a square-planar coordination geometry and the molecules are stacked with a separation of 11.056(3) $\AA$ between the neighboring $\mathrm{Zn}$ centers along the crystallographic $b$-axis.
\end{abstract}

(Received April 14, 2005; Accepted July 20, 2005; Published on web September 9, 2005)

The porphyrin derivatives containing reactive terminal-alkene groups are important for practical applications of porphyrinbased optoelectronic materials and devices, because the hybrid porphyrin/semiconductor architectures require the ability to attach the porphyrins to an electroactive surface in a reliable and robust manner. ${ }^{1}$ The porphyrins with terminal-alkene groups are also useful building blocks to construct nano-structured oligoporphyrins through olefin-metathesis using Grubbs catalysts. $^{2}$ We here report on the crystal structure of mesotetrakis $\{[4-($ allyloxy)phenyl]porphyrinato $\}$ zinc(II), (I).

The title compound I was prepared by the reaction of 5,10,15,20-tetrakis[(4-hydroxyphenyl)porphyrinato]zinc(II) with allyl iodide in the presence of anhydrous $\mathrm{Cs}_{2} \mathrm{CO}_{3}$. The spectroscopic data are identical to those in the literature. ${ }^{3}$ Single crystals suitable for X-ray crystallography were grown by the slow diffusion of hexane into a solution of $\mathbf{I}$ in $\mathrm{CH}_{2} \mathrm{Cl}_{2}$ at room temperature. The crystal and experimental data are given in Table 1. The structures were solved by direct methods and refined with anisotropic temperature factors for non-hydrogen

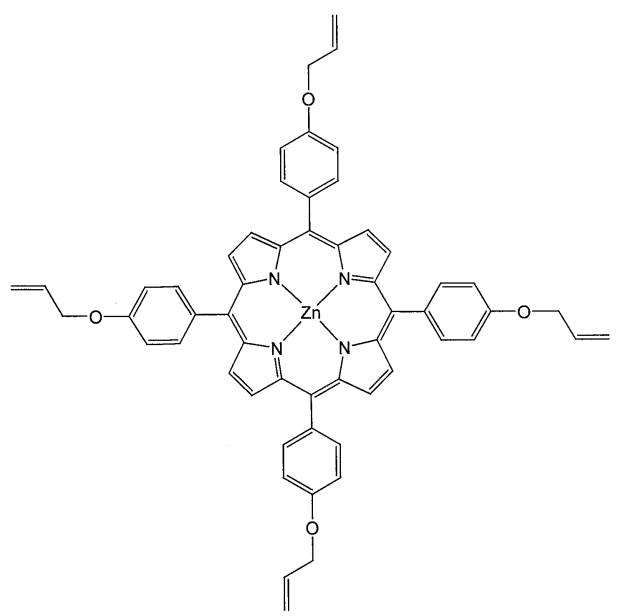

Fig. 1 Chemical structure for $\mathbf{I}$.

$\doteqdot$ To whom correspondence should be addressed.

E-mail: hjk@kumoh.ac.kr atoms. All of the hydrogen atoms were placed in idealized positions and refined using a riding model. The atomic coordinates for non-hydrogen atoms are listed in Table 2. The selected bond lengths and bond angles are summarized in Table 3. The molecular structure of $\mathbf{I}$ with the atom-numbering scheme is given in Fig. 2.

In the crystal structure of $\mathbf{I}$, the $\mathrm{Zn}$ atom lies on an inversion

Table 1 Crystal and experimental data

Formula: $\mathrm{C}_{56} \mathrm{H}_{44} \mathrm{~N}_{4} \mathrm{O}_{4} \mathrm{Zn}$

Formula weight $=902.32$

Temperature: $173(2) \mathrm{K}$

Crystal size: $0.40 \times 0.30 \times 0.20 \mathrm{~mm}$

Crystal color: red

Crystal description: block

Crystal system: monoclinic

Space group: $P 2_{1} / n \quad Z=2$

$a=9.898(2) \AA$

$b=11.056(3) \AA$

$c=20.187(5) \AA$

$\beta=96.863(5)^{\circ}$

$V=2193.2(9) \AA^{3}$

$D_{\text {x }}=1.366 \mathrm{~g} / \mathrm{cm}^{3}$

Radiation: $0.71073 \AA\left(\right.$ Mo $\left.K_{\alpha}\right)$

$2 \theta_{\max }=56.76^{\circ}$

$R=0.0644$

$w R=0.1337$

Goodnees-of-fit $=0.934$

$(\Delta / \sigma)_{\max }$ final cycle: 0.001

$(\Delta \rho)_{\max }=0.675 \mathrm{e}^{-3}$

$(\Delta \rho)_{\min }=-0.523 \mathrm{e}^{-3}$

No. of reflections used $=4492[>2 \sigma(I)]$

No. of parameters $=295$

Diffractometer: Bruker SMART CCD system

Monochromator: graphite

Structure determination: SHELXTL 5

Refinement: full-matrix least-squares

CCDC 275933 contains the supplementary crystallographic data for this paper. These data can be obtained free of charge from The Cambridge Crystallographic Data Centre via www.ccdc.cam.ac.uk/data_request/cif. 
Table 2 Atomic coordinates $\left(\times 10^{4}\right)$ and equivalent isotropic displacement parameters $\left(\AA^{2} \times 10^{3}\right)$

\begin{tabular}{|c|c|c|c|c|}
\hline Atom & $x$ & $y$ & $z$ & $U(\mathrm{eq})$ \\
\hline $\mathrm{Zn}$ & 10000 & 0 & -5000 & $31(1)$ \\
\hline $\mathrm{O}(1)$ & $7350(4)$ & $-1331(3)$ & $-896(2)$ & $49(1)$ \\
\hline $\mathrm{O}(2)$ & $13445(4)$ & $7287(3)$ & $-3512(2)$ & $47(1)$ \\
\hline $\mathrm{N}(1)$ & $9018(4)$ & $-1392(3)$ & $-4603(2)$ & $32(1)$ \\
\hline $\mathrm{N}(2)$ & $10115(4)$ & $900(3)$ & $-4117(2)$ & $30(1)$ \\
\hline $\mathrm{C}(1)$ & $8555(5)$ & $-2443(4)$ & $-4919(2)$ & $33(1)$ \\
\hline $\mathrm{C}(2)$ & $7841(5)$ & $-3150(4)$ & $-4475(2)$ & $38(1)$ \\
\hline$C(3)$ & $7871(5)$ & $-2538(4)$ & $-3898(2)$ & $38(1)$ \\
\hline $\mathrm{C}(4)$ & $8626(5)$ & $-1443(4)$ & $-3970(2)$ & $34(1)$ \\
\hline$C(5)$ & $8926(5)$ & $-567(4)$ & $-3464(2)$ & $35(1)$ \\
\hline$C(6)$ & $9620(5)$ & $516(4)$ & $-3540(2)$ & $35(1)$ \\
\hline$C(7)$ & $9937(5)$ & $1413(4)$ & $-3024(2)$ & $38(1)$ \\
\hline $\mathrm{C}(8)$ & $10579(5)$ & 2331(4) & $-3289(2)$ & $38(1)$ \\
\hline $\mathrm{C}(9)$ & $10675(5)$ & $2025(4)$ & $-3979(2)$ & $33(1)$ \\
\hline $\mathrm{C}(10)$ & $11299(5)$ & $2751(4)$ & $-4421(2)$ & $32(1)$ \\
\hline $\mathrm{C}(11)$ & $8484(5)$ & $-829(4)$ & $-2797(2)$ & $36(1)$ \\
\hline$C(12)$ & 9034(5) & $-1789(4)$ & $-2411(2)$ & $37(1)$ \\
\hline$C(13)$ & $8669(5)$ & $-2010(4)$ & $-1778(2)$ & $39(1)$ \\
\hline$C(14)$ & $7728(5)$ & $-1246(4)$ & $-1523(2)$ & $39(1)$ \\
\hline$C(15)$ & $7151(6)$ & $-318(4)$ & $-1913(3)$ & $45(1)$ \\
\hline$C(16)$ & $7522(5)$ & $-107(4)$ & $-2538(2)$ & $44(1)$ \\
\hline$C(17)$ & $7663(6)$ & $-2412(5)$ & $-516(3)$ & $49(1)$ \\
\hline$C(18)$ & $9077(7)$ & $-2491(5)$ & $-186(3)$ & $54(2)$ \\
\hline$C(19)$ & $9830(7)$ & $-3459(6)$ & $-193(3)$ & $71(2)$ \\
\hline$C(20)$ & $11826(5)$ & $3969(4)$ & $-4174(2)$ & $30(1)$ \\
\hline$C(21)$ & $13189(6)$ & $4134(4)$ & $-3983(3)$ & $43(1)$ \\
\hline $\mathrm{C}(22)$ & $13703(6)$ & $5246(4)$ & $-3756(3)$ & $44(1)$ \\
\hline$C(23)$ & $12834(6)$ & $6219(4)$ & $-3734(2)$ & $36(1)$ \\
\hline$C(24)$ & $11463(6)$ & $6071(4)$ & $-3917(2)$ & $37(1)$ \\
\hline$C(25)$ & 10967(5) & $4938(4)$ & $-4138(2)$ & $37(1)$ \\
\hline$C(26)$ & $12637(7)$ & $8332(4)$ & $-3523(3)$ & $61(2)$ \\
\hline $\mathrm{C}(27)$ & $13606(8)$ & $9388(5)$ & $-3345(3)$ & $79(2)$ \\
\hline $\mathrm{C}(28)$ & $13442(9)$ & $10173(6)$ & $-2923(4)$ & 101(3) \\
\hline
\end{tabular}

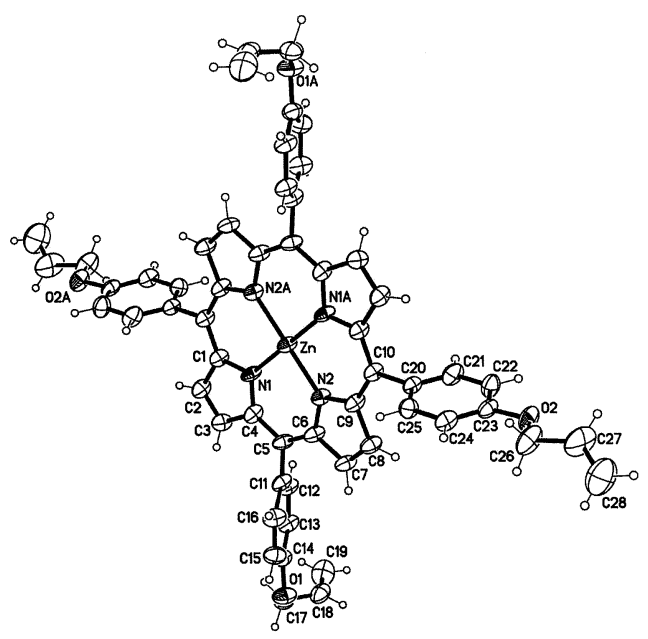

Fig. 2 Molecular structure of $\mathbf{I}$ with the atom-numbering scheme. Displacement ellipsoids are shown at the $30 \%$ probability level.

center at a special position and adopts a square-planar coordination geometry with essentially identical distances of Zn-N1 [2.035(4)Å] and Zn-N2 [2.033(3)Å]. The porphyrin core, consisting of 24 atoms, is nearly planar; the deviation of the individual atoms from the mean plane does not exceed 0.01 $\AA$. The meso phenyl rings attached to the $\mathrm{C}$ atoms $\mathrm{C} 5$ and $\mathrm{C} 10$ make dihedral angles of 64.4 (1) and 79.1(1) ${ }^{\circ}$ with the core, respectively. The torsion angles of the allyloxy chains in $\mathbf{I}$
Table 3 Selected bond lengths $(\AA)$ and angles $\left({ }^{\circ}\right)$

\begin{tabular}{lclc}
\hline Zn-N1 & $2.035(4)$ & Zn-N2 & $2.033(3)$ \\
C14-O1 & $1.365(5)$ & C23-O2 & $1.377(5)$ \\
O1-C17 & $1.433(6)$ & O2-C26 & $1.404(6)$ \\
C17-C18 & $1.479(8)$ & C26-C27 & $1.526(8)$ \\
C18-C19 & $1.305(8)$ & C27-C28 & $1.241(9)$ \\
& & & \\
N1-Zn-N2 & & & \\
C14-O1-C17 & $119.2(4)$ & C23-O2-C26 & $118.2(4)$ \\
O1-C17-C18 & $115.1(4)$ & O2-C26-C27 & $106.5(5)$ \\
C17-C18-C19 & $123.7(6)$ & C26-C27-C28 & $124.5(8)$ \\
\hline
\end{tabular}

Symmetry code: (i) $-x+2,-y,-z-1$.

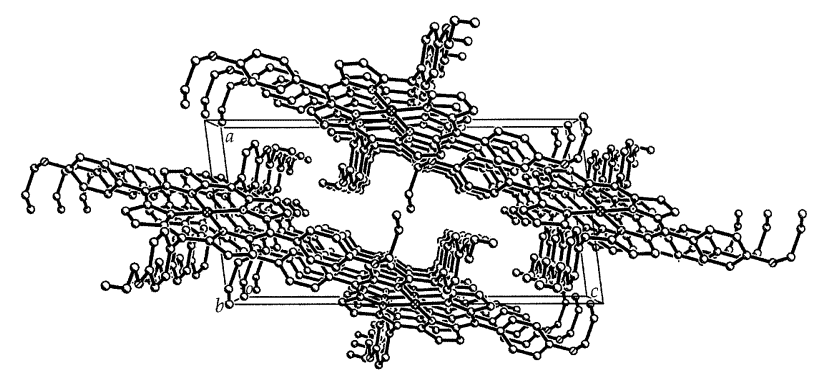

Fig. 3 Perspective packing view of $\mathbf{I}$ down the crystallographic $b$ axis. $\mathrm{H}$ atoms have been omitted for clarity.

$[\mathrm{O} 1-\mathrm{C} 17-\mathrm{C} 18-\mathrm{C} 19=134.7(6)$ and $\mathrm{O} 2-\mathrm{C} 26-\mathrm{C} 27-\mathrm{C} 28=$ $\left.131.6(8)^{\circ}\right]$ indicate that there is no intramolecular $\mathrm{C}-\mathrm{H} \cdots \mathrm{O}$ interaction, as implied in the planar arrangement of an allyloxy chain. ${ }^{4}$

The unit-cell packing along the $b$-axis is shown in Fig. 3. The porphyrin rings are arranged in tilted stacks along the $b$-axis with no significant $\pi-\pi$ interactions among the porphyrin rings. The separation between neighboring $\mathrm{Zn}$ centers along the $b$-axis amounts to $11.056(3) \AA$. The phenyl groups with allyloxy chains around the porphyrin rings may be obstructive for stacking through efficient $\pi-\pi$ interactions between the porphyrin rings.

\section{Acknowledgements}

This work was supported by Kumoh National Institute of Technology. A single-crystal X-ray analysis was performed using a Bruker SMART CCD diffractometer at the Central Laboratory, Gyeongsang National University.

\section{References}

1. Z. Liu, A. A. Yasseri, R. S. Loewe, A. B. Lysenko, V. L. Malinovskii, Q. Zhao, S. Surthi, Q. Li, V. Misra, J. S. Lindsey, and D. F. Bocian, J. Org. Chem., 2004, 69, 5568.

2. T. Inomata and K. Konishi, Chem. Commun., 2003, 1282.

3. J. S. Lindsey, I. C. Schreiman, H. C. Hsu, P. C. Kearney, and A. M. Margurettaz, J. Org. Chem., 1987, 52, 827.

4. P. Kirsop, J. M. D. Storey, and W. T. A. Harrison, Acta Cryst., 2004, E60, o1147.

5. Siemens: Structure Determination Programs. Version 5.03 in SHELXTL. Siemens Analytical X-ray Instruments Inc., Madison, Winsconsin, USA, 1997. 